\title{
REVIEW
}

\section{Clinical review: Critical care medicine in mainland China}

\author{
Bin Du*1, Xiuming Xi'2, Dechang Chen ${ }^{1}$ and Jinmin Peng'; on behalf of China Critical Care Clinical Trial Group (CCCCTG)
}

\begin{abstract}
Critical care medicine began in mainland China in the early 1980s. After almost 30 years of effort, it has been recognized as a specialty very recently. However, limited data suggest that critical care resources, especially ICU beds, are inadequate compared with those of developed countries. National critical care societies work together to set up good practice standards, and to improve academic levels with scientific meetings, education programs, and training courses. Critical care research in mainland China is beginning to evolve, with great potential for improvement.
\end{abstract}

\section{Healthcare in China}

During the past three decades - the era of economic liberalization in mainland China - China has had one of the world's fastest growing economies. However, healthcare development in China is far behind its economic growth. The performance of China's healthcare system was rated poorly compared to that of other countries according to The World Health Report 2000 - Health Systems: Improving Performance [1].

In China, total healthcare expenditure accounts for $4.5 \%$ to $5.6 \%$ of gross domestic product (Table 1). Although the trend shows that an increasing proportion of total healthcare expenditure has been funded by the government since 2001, the government paid only $20.3 \%$ of the expenditure in 2007 [2,3]. On the other hand, the urban basic healthcare insurance program in China is still in a development period, covering only 359.5 million people (52.2\% of the urban population, or $27.1 \%$ of the total population) in 2008 [3]. However, other forms of insurance program are under development, especially in rural areas.

*Correspondence: dubin98@gmail.com

'Medical ICU, Peking Union Medical College Hospital, Peking Union Medical

College and Chinese Academy of Medical Sciences, 1 Shuai Fu Yuan,

Beijing 100730, China

Full list of author information is available at the end of the article
Healthcare in mainland China is not cheap. The annual cost of medical care for a citizen in China increased from US dollars (USD) 42.9 in 2001 to USD 125.7 in 2008, corresponding to $7.2 \%$ and $10.1 \%$ of annual income per capita, respectively (Table 1 ).

\section{History of critical care medicine in mainland China}

Although advanced life support techniques, especially positive pressure ventilation, inspired the development of critical care medicine in Europe and North America in the 1950s, critical care medicine is still one of the newest disciplines of clinical medicine in mainland China.

As in many other countries, critical care was initially practiced in a variety of postoperative recovery rooms and/or an isolation area within the general ward. It is well recognized that the first ICU in mainland China was set up in the Peking Union Medical College Hospital in 1982, in the form of a surgical ICU with only one bed $[4,5]$. Two years later, it became the first Department of Critical Care Medicine in mainland China, with a seven-bed general ICU in the Peking Union Medical College Hospital, chaired by Dr Dechang Chen, the well-recognized founding father of critical care medicine in mainland China.

In November 1989, the Ministry of Health issued the Regulation of Hospital Accreditation and Management, which required the establishment of an ICU as a prerequisite for accreditation as a tertiary hospital $[4,5]$. Many ICUs were set up in hospitals all over China following the release of this document. Many physicians (including general surgeons, internists, emergency physicians, and anesthesiologists) were sent to other hospitals for critical care training, either abroad or domestically, before returning to practice as intensivists $[4,5]$.

\section{Development of critical care medicine as a specialty in mainland China}

In mainland China, physicians of other relevant specialties were the first to be assigned to work in ICUs because of their familiarity with the necessary techniques (anesthesiologists), disease entities (surgeons and internists), and required urgency of treatment (emergency physicians). However, after years of hard work, the important role of intensivists, as a coordinator during patient 
Table 1. Summary of healthcare in China $[2,3]$

\begin{tabular}{|c|c|c|c|c|c|}
\hline & \multicolumn{5}{|c|}{ Year } \\
\hline & 2001 & 2003 & 2005 & 2007 & 2008 \\
\hline Population (million) & $1,276.27$ & $1,292.27$ & $1,307.56$ & $1,321.29$ & $1,328.02$ \\
\hline Urban (\%) & 37.7 & 40.5 & 43.0 & 44.9 & 45.7 \\
\hline Rural (\%) & 62.3 & 59.5 & 57.0 & 55.1 & 54.3 \\
\hline GDP (million USD) & 1,405 & 1,709 & 2,669 & 3,611 & 4,402 \\
\hline GDP per capita (USD) & 1,101 & 1,322 & 2,041 & 2,733 & 3,315 \\
\hline Annual income per capita (USD) & 594 & 731 & 932 & 1,240 & 1,434 \\
\hline Urban (USD) & 1,004 & 1,240 & 1,536 & 2,018 & 2,311 \\
\hline Rural (USD) & 346 & 384 & 477 & 606 & 697 \\
\hline Total healthcare expenditure (million USD) & 75.4 & 96.4 & 126.8 & 165.3 & NA \\
\hline Percentage of GDP spent on healthcare & 5.37 & 5.64 & 4.75 & 4.58 & NA \\
\hline Percentage of total healthcare expenditure funded by the government & 15.5 & 17.0 & 17.9 & 20.3 & NA \\
\hline Percentage of total healthcare expenditure funded by individuals & 60.5 & 55.8 & 52.2 & 45.2 & NA \\
\hline \multicolumn{6}{|l|}{ Population covered by insurance (million) } \\
\hline Urban & 76.3 & 109.0 & 137.1 & 220.5 & 317.0 \\
\hline Rural & NA & NA & NA & 31.3 & 42.5 \\
\hline \multicolumn{6}{|l|}{ Cost of medical care (USD) } \\
\hline Per visit & 13.7 & 15.8 & 18.6 & 19.9 & 21.4 \\
\hline Per admission & 475.2 & 572.6 & 682.5 & 728.2 & 800.0 \\
\hline \multicolumn{6}{|l|}{ Annual medical service per capita } \\
\hline Visit & 1.64 & 1.62 & 1.76 & 2.52 & 2.66 \\
\hline Admission & 0.043 & 0.047 & 0.052 & 0.074 & 0.086 \\
\hline \multicolumn{6}{|l|}{ Annual cost of medical care (USD) } \\
\hline Per capita & 42.9 & 52.5 & 68.0 & 104.0 & 125.7 \\
\hline Percentage of annual income & 7.2 & 7.2 & 7.3 & 8.4 & 10.1 \\
\hline
\end{tabular}

GDP, gross domestic product; NA, not available; USD, US dollars. 1 USD $=6.83$ RMB.

evaluation and treatment, has gradually been recognized and respected by other specialties. Junior physicians interested in critical care training can choose to be intensivists after they finish 3 or 4 years of fellowship training in surgery or internal medicine. However, the traditional specialties often still assume responsibility for or 'ownership' of patients, as well as have a desire to treat critically ill patients, as reflected by the fact that the proposal for setting up a critical care society under the Chinese Medical Association (CMA) was rejected in 1996.

Public healthcare crises in China since 2003 have provided intensivists with an opportunity to demonstrate their knowledge and skills. Epidemics of severe acute respiratory syndrome (SARS) in 2003, of Streptococcus suis in 2005, and of avian influenza, as well as the Wenchuan Earthquake in 2008, caused extreme anxiety in the public due to the vulnerability of the general population, the high communicability of the diseases, and the high case fatality rate. Therefore, intensivists were often convened by the government to be involved in crisis management very early [6]. Their ability to coordinate, cooperate, and communicate with regard to both patient management and policy-making was well demonstrated during daily work, and recognised by the general public and healthcare authorities. As a result, critical care medicine was officially recognized as a specialty of clinical medicine in 2009 [7].

\section{Critical care resources and services}

There is no census on critical care resources in China, including the number of ICUs, intensivists, ICU nurses, and relevant facilities (for example, bedside monitors, artificial ventilators), because no national survey has ever been performed.

We performed computerized literature searches of the China Academic Journals Full-text Database of the China National Knowledge Infrastructure. We used the search terms 'intensive care unit' or 'intensive care' or 'critical care unit' and 'survey', and found only eight relevant papers concerning critical care resources in mainland 
Table 2. Critical care resources in mainland China [8-16]

\begin{tabular}{lcccccccccc}
\hline Ref. & $\begin{array}{c}\text { Year of } \\
\text { survey }\end{array}$ & Region & $\begin{array}{c}\text { Number } \\
\text { of } \\
\text { hospitals }\end{array}$ & $\begin{array}{c}\text { Number } \\
\text { of hospital } \\
\text { beds }\end{array}$ & $\begin{array}{c}\text { Number } \\
\text { of } \\
\text { ICUs }\end{array}$ & $\begin{array}{c}\text { Total } \\
\text { ICU } \\
\text { beds }\end{array}$ & $\begin{array}{c}\text { Percentage } \\
\text { hospital } \\
\text { beds }\end{array}$ & $\begin{array}{c}\text { Average } \\
\text { ICU } \\
\text { beds }\end{array}$ & $\begin{array}{c}\text { Number of } \\
\text { intensivists } \\
\text { per ICU }\end{array}$ & $\begin{array}{c}\text { Number of } \\
\text { nurses } \\
\text { per ICU }\end{array}$ \\
\hline$[8]^{\mathrm{d}}$ & 1999 & 25 provinces & 155 & 90,848 & 316 & 1,934 & 2.1 & $6.4 \pm 4.8$ & $5.9 \pm 3.4$ & $11.0 \pm 6.5$ \\
{$[9]^{\mathrm{b}}$} & 2001 & 17 provinces & 27 & 9,023 & 44 & 527 & 5.3 & 12 & 9.0 & 16.4 \\
{$[10]^{\mathrm{c}}$} & 2005 & Jiangsu & 61 & 41,759 & 180 & 548 & 1.4 & 9.0 & 6.3 & 14.5 \\
{$[11]^{\mathrm{d}}$} & 2005 & Beijing & 64 & $\mathrm{NA}$ & 126 & 1,092 & $\mathrm{NA}$ & 8.7 & 6.2 & 14.8 \\
{$[12]^{\mathrm{e}}$} & 2006 & Guangdong & 41 & 39,205 & 43 & 572 & $1.6 \pm 0.9$ & $13.3 \pm 7.4$ & $8.9 \pm 3.6$ & $25.3 \pm 6.6$ \\
{$[13]^{\mathrm{f}}$} & 2006 & Guangdong & 26 & 13,443 & 26 & 263 & $2.1 \pm 0.8$ & $10.1 \pm 3.8$ & $7.5 \pm 2.5$ & $18.2 \pm 5.8$ \\
{$[14]^{g}$} & 2007 & Guangxi & 34 & 22,425 & 34 & 281 & $1.4 \pm 0.5$ & $8.3 \pm 4.0$ & $7.3 \pm 3.1$ & $15.6 \pm 4.1$ \\
{$[15]^{\mathrm{h}}$} & 2008 & Shandong & 139 & 77,665 & 196 & 1,702 & $2.2 \pm 1.8$ & $8.7 \pm 5.9$ & $6.9 \pm 6.4$ & $16.1 \pm 10.1$ \\
{$[16]^{\mathrm{j}}$} & 2009 & 21 provinces & 24 & 46,752 & 24 & 499 & $1.1 \pm 0.5$ & $20.8 \pm 14.1$ & $13.2 \pm 10.6$ & $42.1 \pm 32.1$ \\
\hline
\end{tabular}

aResponse rate $15.3 \%$ (155 out of 1,210). ${ }^{b}$ Response rate $68 \%$ ( 27 out of 40 ), including 18 pediatric ICUs, 20 neonatal ICUs, and 6 mixed ICUs. Including 30 tertiary hospitals and 31 local hospitals. IIncluding 106 ICUs in 46 tertiary hospitals and 20 ICUs in 18 local hospitals. eSurvey in tertiary hospitals. fSurvey in local hospitals. gIncluding 22 ICUs in 22 tertiary hospitals and 12 ICUs in 17 local hospitals. "Including 87 ICUs in 50 tertiary hospitals and 109 ICUs in 89 local hospitals. 'Data from 24 ICUs of 24 tertiary hospitals in 21 provinces. NA, not available.

China [8-15] that were published within the past decade (Table 2). Unfortunately, none of these eight papers selected a representative sample of ICUs in China.

Table 2 summarizes data from these eight papers [815], in addition to those of the China Critical Care Clinical Trial Group (CCCCTG) [16]. Based on the above data, we made a rough estimation that, in mainland China, ICU beds might account for $1.8 \%$ (interquartile range $1.3 \%$ to $2.1 \%$ ) of total hospital beds [8-10,12-16]. In 2008, the Ministry of Health reported that there were a total of 2,882,862 beds in 19,712 hospitals in China [3]. Therefore, we estimate that there were $51,891(37,477$ to 60,540) ICU beds in China in 2008, corresponding to 3.91 (2.82 to 4.56) ICU beds per 100,000 population, with 217 hospital beds per 100,000 population. This figure is comparable to that of the United Kingdom (3.5 ICU beds per 100,000 population), which was the lowest of eight countries in North America and Western Europe [17].

Among all ICUs, about half were closed (mean 51.6\%, range $45 \%$ to $73.5 \%$ ), more than one-third were semiclosed (mean $36.3 \%$, range $26.9 \%$ to $41.9 \%$ ), and the others were open ICUs (mean $12.1 \%$, range $0 \%$ to $18 \%$ ) [8-10,12-15]. The relative distribution of specialty ICUs versus general ICUs was not uniform across the country, with specialty ICUs making up from 35\% (Shandong) to $66 \%$ (Jiangsu) of units, or $34 \%$ (Shandong) to $53 \%$ (Beijing) of ICU beds $[10,11,15]$.

In addition, the ICU nurse-to-bed ratio ranged from 1.37 to 2.02 [8-16], corresponding to 71,091 to 104,820 ICU nurses in mainland China. According to limited data, there is no significant difference in ICU beds and nurse-to-bed ratios between coastal areas and inland areas. Although there are usually more ICU beds in tertiary hospitals than local hospitals, there is no difference in nurse-to-bed ratio. Even few data are available for bedside monitors, mechanical ventilators, and dialysis machines, which preclude the possibility of making any estimation.

There has been no large-scale observational study about case mix in Chinese ICUs, although some data are available. Among 443 patients receiving mechanical ventilation for more than 48 hours in 26 ICUs, mean age was $62.4 \pm 19.5$ years, and $298(67.3 \%)$ were male [18]. Medical reasons accounted for $58.2 \%$ of all ICU admissions, followed by emergency surgery (22.8\%), and elective surgery (19.0\%) [18]. Data from the CCCCTG showed that, among 38,922 patients admitted to 24 ICUs in 2007 and 2008, about two-thirds $(66.2 \pm 23.0 \%)$ were treated with invasive mechanical ventilation, pulmonary artery catheters or arterial pulse contour analysis was used in $2.9 \pm 3.6 \%$ of patients, and continuous renal replacement therapy was used in $12.2 \pm 11.4 \%$ of patients [19]. The hospital mortality rate was $13.1 \pm 8.6 \%$ [19].

A 12-month prospective observational study in 10 surgical ICUs identified $8.68 \%(318 / 3,665)$ of patients had severe sepsis, with a hospital mortality rate of $48.7 \%$ [20]. Prospective and retrospective observational studies suggested that $2.0 \%$ to $25.1 \%$ of ICU patients developed acute respiratory distress syndrome [18,21-23]; the hospital mortality rate ranged from $52.0 \%$ to $68.5 \%$ [21-23]. The mean hospital cost for severe sepsis was USD $11,390 \pm 11,455$, and the mean daily cost was USD $502 \pm 401$ [20], corresponding to $794 \%$ and $35 \%$ of annual income per capita in 2008 (Table 1).

\section{National critical care societies}

As mentioned above, anesthesiologists, general surgeons, emergency physicians and pulmonologists are all involved in ICU management in mainland China. Their influence is well described by the presence of critical care sections 
within the associated professional societies, namely, the Chinese Society of Anesthesiology, Chinese Society of Surgery, Chinese Society of Emergency Medicine, and Chinese Society of Respiratory Diseases.

Although the CMA refused to set up a critical care society in 1996, the first national critical care society in mainland China was established in 1997, called the Chinese Society of Critical Care Medicine (CSCCM), and currently has about 500 members. The major objective of the CSCCM is to provide a multidisciplinary platform for promoting critical care medicine all over China, provide expert opinion to the government and other bodies, and encourage both national and international academic exchange.

The CSCCM organizes a 3-day biennial national conference, with attendees increasing from 200 in 1997 to more than 1,000 people in 2006, including physicians, nurses, and company representatives. In 2006, the CSCCM hosted the 14th International Congress of the Asia Pacific Association of Critical Care Medicine (APACCM) in Beijing. The scientific program included 16 plenary lectures, 130 lectures and workshops by 57 speakers from 19 countries. This was the first time that an international conference on critical care medicine had ever been held in mainland China, a milestone demonstrating more involvement in the international community.

Since its establishment, the CSCCM has developed close relationships with multiple international professional societies, such as the Society of Critical Care Medicine (SCCM), the European Society of Intensive Care Medicine, the Société de Réanimation de Langue Française, the APACCM, and the World Federation of Societies of Intensive and Critical Care Medicine (WFSICCM). Right now, the CSCCM is the only member society representing mainland China in both the WFSICCM and APACCM.

The second national critical care society, the Chinese Society of Intensive Care Medicine, was established in 2005 under the CMA (CSICM-CMA). CSICM-CMA has been working actively to enact clinical practice guidelines, including nutritional support, mechanical ventilation, and sepsis management.

The third national critical care society, the Chinese Association of Critical Care Physicians (CACCP), was founded in July 2009. As an affiliation to the China Medical Doctors Association, the aim of the CACCP will include professional certification of intensivists.

These three societies have the common philosophy to cooperate with each other in the future because they share almost the same leadership.

\section{Training of critical care physicians, nurses and respiratory therapists}

At present, there is no formal accredited critical care training program in China. Residents can choose critical care medicine as their specialty after graduation from medical school. Rotation in other departments, such as anesthesia or internal medicine, is not obligatory, and is organized according to institution and department requirements. On the other hand, residents may consider critical care medicine as a subspecialty after finishing a fellowship training program in internal medicine, anesthesia, general surgery, or emergency medicine.

ICU physicians can register as intensivists (for those working in general ICUs), or, alternatively, remain registered under their primary specialty of anesthesiology, internal medicine, general surgery or emergency medicine (for those working in specialized ICUs) [7].

In mainland China, most nursing education programs employ only a 3-year curriculum after senior high school. Although colleague education programs have become more and more popular, there is still a significant demand for professional education for nurses. In 2003, the Beijing Nursing Association started to implement a critical care nurse certification program, with around 150 trainees every year. The program is composed of 1 month of lectures and 1 month of clinical practice, followed by examination of knowledge and skills. Trainees are also required to finish a review before certificates are issued. In 2007, the China Nursing Association followed the same model in order to meet the need in other cities in mainland China.

Respiratory therapists are present in only a few ICUs. Sichuan University set up the first program of respiratory therapy in a medical school in mainland China in 2002 [24].

\section{Future development of critical care medicine in mainland China}

The lack of a national accredited critical care training program is believed to be a major obstacle for improving professional education in China. Although access to state-of-the-art advances might be available during national and international conferences, basic knowledge and skills are inadequately, and sometimes incorrectly, taught in many hospitals. For the past 5 years, the CSCCM has dedicated itself to promoting professional education with regard to basic knowledge and skills in critical care medicine. The CSCCM successfully organizes a Fundamental Critical Care Support course, a Fundamental Disaster Management course, and a Multiprofessional Critical Care Review Course, with support from the SCCM. In 2007, the CSCCM endorsed the Basic Assessment and Support Intensive Care course, and promoted the course in mainland China. Nine provider courses have been organized until November 2009, with more than 220 participants. However, an advanced training program is still under development, and the number of trainees is very limited compared with the large number of intensivists in mainland China. 
Moreover, a national board exam for critical care medicine is not yet available, which suggests that we do not have a minimum national standard for intensivists.

Critical care research in mainland China is in its infancy. Most study results are published in national medical journals in the Chinese language, while very few investigators succeed in publishing their studies in peerreviewed international medical journals. Possible reasons might include: inadequate training and experience in clinical research; inadequate staffing dedicated to research; inadequate funding for critical care research; and inadequate language proficiency.

However, Chinese intensivists have become more actively involved in international multicenter studies during recent years. For example, a total of 1,135 patients in 57 ICUs in mainland China were enrolled in an observational study, accounting for $21 \%$ of patients and $14 \%$ of ICUs (S Finfer, unpublished data). This suggests a great potential for future improvement in clinical research in mainland China.

Considering the above limitations and potential improvement, we do believe that Chinese intensivists may benefit from academic exchange with the international medical community with regard to the following: development of a series of training programs fulfilling international standards; development of a national board exam for critical care medicine; and conduction of multicenter trials compatible with good clinical practice.

\section{Conclusion}

Overall, critical care medicine in mainland China is still in a phase of development. After years of dedicated hard work, critical care medicine has been recognized as a specialty by the government and other specialties. However, due to scarce resources and limited experience, critical care training and clinical research are still underdeveloped, which also represents a great potential for future improvement.

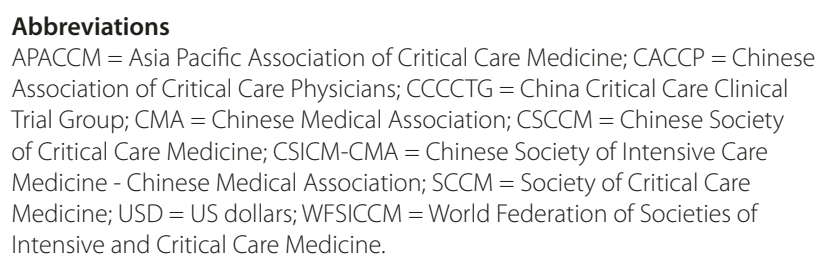

\section{Author details}

'Medical ICU, Peking Union Medical College Hospital, Peking Union Medical College and Chinese Academy of Medical Sciences, 1 Shuai Fu Yuan, Beijing 100730, China

2Department of Critical Care Medicine, Fuxing Hospital, Capital University of Medical Sciences, 20A Fuxingmenwai Avenue, Beijing 100038, China

\section{Competing interests}

The authors declare that they have no competing interests.

Published: 25 February 2010
References

1. World Health Organization: The World Health Report 2000. Health Systems: Improving Performance. Geneva: World Health Organization; 2000.

2. National Bureau of Statistics of China: Statistical communique of the People's Republic of China on the 2008 National Economic and Social Development [http://www.stats.gov.cn/tjgb/ndtjgb/qgndtjgb/ t20090226_402540710.htm]

3. Center of Statistics and Information, Ministry of Health: Statistical communiqué of People's Republic of China on the 2008 National Healthcare Development [http://www.moh.gov.cn/publicfiles/business/ htmlfiles/mohwsbwstjxxzx/s8208/200904/40250.htm]

4. Qiu H, Chen D, Chen J: On exploration into critical care medicine and disciplinary construction. Chin J Hosp Admin 2001, 17:83-85.

5. Wang Y, Ma P: The emergence and development of ICU. Med Philosophy 2006, 27:7-9.

6. Du B, Xi X, Kang Y, Weng L: on behalf of the China Critical Care Clinical Trial Group: Natural disaster. In Intensive and Critical Care Medicine: WFSICCM World Federation of Societies of Intensive and Critical Care Medicine. Edited by Gullo A, Besso J, Lumb PD, Williams GE. Milan: Springer-Verlag Italia; 2009:379-390.

7. Ministry of Health of the People's Republic of China [http://www.moh.gov. cn/publicfiles/business/htmlfiles/mohyzs/s3577/200902/38935.htm]

8. Yin P, Huang Y, Wu K, Xi X, Chen D: The first questionnaire survey of present situation of intensive care unit in whole country. Chin Crit Care Med 2002, 14:166-168.

9. Zhang Y, Fan X: The survey of ICU for neonates and children in China. Chin J Emerg Med 2003, 12:352-354.

10. Li G, Wan J, Wang J, Wang X, Xu X: A questionnaire survey of present situation of ICU in Jiangsu province. Chin J Emerg Med 2006, 15:1071-1074.

11. Jiang $L, X i X$, Du B, Zhou J: Investigation on establishment and management of intensive care units in 64 hospitals in Beijing. Chin J Hosp Admin 2007, 23:397-399.

12. Wu M, Zhao X, Chen Q, Wu Y, Hu S: A survey of general intensive care units in Guangxi. J Guangxi Med Univ 2008, 25:314-317.

13. Guo Q, Li Y, Qin T, Wu H, Guan X, Xu Y, Jiang M, Xiao Z: Survey of present situation of intensive care unit in hospitals and construction of intensive care network in Guangdong Province. Chin J Emerg Med 2008, 17:93-97.

14. Guo Q, Li Y, Qin T, Wu H, Guan X, Xu Y, Jiang M, Xiao Z: A survey of present situation of general intensive care unit in second grade hospitals and construction of intensive care network in Guangdong province. Zhongguo Wei Zhong Bing Ji Jiu Yi Xue 2007, 19:619-622.

15. Wang $C$, Jiang J, Zhang J, Meng M, Ren $H, C$ Chu Y, Yu J: The questionnaire survey of present status of intensive care units in Shandong Province. Zhongguo Wei Zhong Bing Ji Jiu Yi Xue 2009, 21:555-557.

16. China Critical Care Clinical Trials Group; CCCCTG participating centers: Summary of clinical information [http://www.cccctg.org/ index/?action-viewnews-itemid-8]

17. Wunsch $H$, Angus DC, Harrison DA, Collange O, Fowler R, Hoste EA, de Keizer NF, Kersten A, Linde-Zwirble WT, Sandiumenge A, Rowan KM: Variation in critical care services across North America and Western Europe. Crit Care Med 2008, 36:2787-2793.

18. Zhou H, Du B, Chai W, Zhou J, Zhuang H, Ding L, Jiang Q, Zhao H, Li H, Zhang Z, Liu R, Zhang J, Li Z, Zhu G, Ren S, Feng M, Qin S, Xu Q, Liu S, Yang X, Zhang N, Lin X, He Z, Li Z, Liu J, Li Y, Xu Y, He W, Gao S: An investigation on current practice of nutrition support for critically ill in Chinese ICU. Parenteral Enteral Nutrition 2009, 16:259-263.

19. China Critical Care Clinical Trials Group; CCCCTG participating centers: Summary of ICU admissions (2007-2008) [http://www.cccctg.org/ index/?action-viewnews-itemid-9]

20. Cheng B, Xie G, Yao S, Wu X, Guo Q, Gu M, Fang Q, Xu Q, Wang D, Jin Y, Yuan S, Wang J, Du Z, Sun Y, Fang $X$ : Epidemiology of severe sepsis in critically ill surgical patients in ten university hospitals in China. Crit Care Med 2007, 35:2538-2546.

21. Lu Y, Song Z, Zhou X, Huang S, Zhu D, Yang C Bai X, Sun B, Spragg R; Shanghai ARDS Study Group: A 12-month clinical survey of incidence and outcome of acute respiratory distress syndrome in Shanghai intensive care units. Intensive Care Med 2004, 30:2197-2203.

22. Li JB, Zhang L, Zhu KM, Deng XM: Retrospective analysis on acute respiratory distress syndrome in ICU. Chin J Traumato/ 2007, 10:200-205.

23. Ge Q, Zhu X, Yao G, Wang C, Yin C, Lv J, Zhang S: Epidemiological investigation on acute respiratory distress syndrome occurring in 
Du et al. Critical Care 2010, 14:206

Page 6 of 6

http://ccforum.com/content/14/1/206

intensive care units in Beijing from 1998 to 2003. Zhongguo Wei Zhong Bing Ji Jiu Yi Xue 2007, 19:201-204.

24. Anonymous: Introduction of program on respiratory therapy, School of Medicine, Sichuan University. Chin J Respir and Crit Care Med 2002, 1:49.

doi:10.1186/cc8222

Cite this article as: Du B, et al.: Critical care medicine in mainland China.

Critical Care 2010, 14:206. 